\title{
새뱅이와 넓적뿔꼬마새우의 생식생물학적 연구
}

\author{
정인주 · 오철웅 ${ }^{1, *} \cdot$ 마채우 $^{2}$ \\ 전남대학교 해양학과, ${ }^{1}$ 독포대학교 해양수산자원학과, ${ }^{2}$ 순천향대학교 생명과학부

\section{Reproductive Biology of Neocaridina denticulata denticulata and Latreutes planirostris}

\author{
In-Ju JEONG, Chul-Woong $\mathrm{OH}^{1, *}$ and Chae-Woo $\mathrm{MA}^{2}$ \\ Department of Oceanography, Chonnam National University, Kwangju 500-757, Korea \\ ${ }^{1}$ Department of Marine Fisheries Resources, Mokpo National University, Muan 534-729, Korea \\ ${ }^{2}$ Division of Life Sciences, Soonchunhyang University, Asan 336-745, Korea
}

\begin{abstract}
We investigated the fecundity, egg size, reproductive output, and breeding frequency and season of Neocaridina denticulata denticulata and Latreutes planirostris which inhabit extremely different habitats. The marine shrimp Latreutes planirostris produced more eggs had at a given carapace length than the freshwater shrimp $N$. $d$. denticulata. However, $N$. $d$. denticulata had a larger egg volume and greater reproductive output than L. planirostris. The monthly gonadosomatic index (GSI) of the freshwater shrimp began to increase in April and reached a maximum in May, suggesting a single breeding period. In contrast, the GSI of the marine shrimp exhibited two breeding peaks: May-June and September. In both shrimps, the regressions between carapace length and ovarian weight were significant at the non-eyed and eyed embryo stages. For both species, an analysis of covariance revealed significant difference between the two regressions in elevation, but not in slope. These results indicate the potential for multiple ovulations within the reproductive season.
\end{abstract}

Key words: Neocaridina denticulata denticulata, Latreutes planirostris, Fecundity, Repreductive output, Breeding frequency

\section{서 론}

해양에 서식하는 무척추동물은 고위도로 갈수록 포란수가 증가하는 경향을 보이며(Thorson, 1950; Clarke, 1979), 난의 크기는 서식처에 따라 다양하게 분화되어 있고 이는 진화론적 관점에서 생물간 적응의 차이로 간주되고 있다(Vance, 1973; Strathmann, 1985). 생활사 유형을 구분짓는 결정적인 요소로 써 생식산출력(Reproductive output)은 암컷 개체의 생체량에 대한 번식에 의해 생산된 생산물의 생체량의 비를 가리키며, 생물 고유의 생존전략을 이해하는데 이용되기도 한다(Clarke, 1979, 1987; Hines, 1982; King and Butler, 1985).

갑각류는 전세계적으로 담수와 기수 및 해수에 넓게 분포하 고 있으며, 서식처에 따라 생식유형이나 생존전랴이 다양하게 분화되어 있다(Hartnoll, 1985). 새뱅이(Neocaridina denticulata denticulata)와 넓적뿔고마새우(Latreutes planirostris)는 성체 의 크기가 유사하고 생태계 먹이사슬 내에서 상위 포식자들의 먹이 공급원과 하위 피식자를 섭이하는 중간단계의 생태적 지위를 차지하고 있지만 담수와 해수라는 상반된 서식처에 분포하는 특징을 지니고 있다. 새뱅이는 대표적인 담수산 새 우로써 우리나라를 비롯한 중국, 일본, 대만 등지의 온대나 열대 지역에 서식하며, 넓적뿔꼬마새우는 우리나라의 서해,

*Corresponding author: chuloh@mokpo.ac.kr
남해안 해역과 동중국해를 공유하는 일본, 중국, 홍콩 등지에 주로 분포한다고 알려져 있다(Holthuis, 1980; Kim, 1977). 이들 두 종에 대한 연구는 각각의 개체군을 대상으로 그들의 번식 생태와 개체군 역학에 관한 연구가 수행되었다(Kamita, 1958; Oh et al., 2003). 서식처에 따라 번식생태에 관련된 특성치가 어떻게 분화되었는지에 관한 연구는 생식전략 측면에서 흥미 로운 연구주제가 되어왔다. 그러나 극단의 환경에 서식하는 갑각류를 대상으로 하여 생식생태학적 차이에 관한 연구는 극히 제한적이다.

본 연구는 새뱅이와 넓적뿔꼬마새우의 포란수와 난의 크기 및 생식산출력을 비교.분석하고 산란시기와 산란빈도의 차이 를 규명함으로써 이들 두 종이 지닌 고유한 번식전략을 이해 하고자 한다.

\section{재료 및 방법}

표본 채집 및 처리

새뱅이와 넓적뿔꼬마새우의 채집은 서식 수심과 장소에 따라 어구를 달리하여 실시하였다. 새뱅이 표본은 영암군 월 출산 주변 계곡에서 2001년 뜰채(Scoop net)를 이용하여 채집 하였고 넓적뿔꼬마새우는 신안군 칠발도 인근해역에서 주머 니얽애그물(Single walled tangle net)을 이용하여 채집하였다. 표본은 채집후 $5 \%$ 중성포르말린으로 고정하고 실험실로 운반 
하여 포란한 개체만을 선별하여 분석에 이용하였다. 포란한 암컷의 체장은 표준체장으로써 눈구멍 끝에서부터 갑각의 끝 가장자리까지 직선거리인 갑각장(Carapace Length: CL)을 쌍안 입체현미경에서 $0.01 \mathrm{~mm}$ 까지 측정하였다.

\section{난과 생식소 관찰}

현미경 하에서 암컷 개체로부터 난을 모두 분리한 후 눈의 유무에 따라 난 발생단계( I 단계: 눈이 없는 난, II 단계: 눈을 가진 난)를 결정한 후 직접 계수하였다. 난의 부피는 개체당 5 개의 난을 무작위로 추출하여 장경과 단경을 측정하여 다음 과 같은 타원의 부피산출 공식을 사용하여 난의 부피 $(\mathrm{V})$ 를 계산하였다.

$$
\mathrm{V}=\frac{4}{3} \pi \mathrm{r}_{1} \mathrm{r}_{2}^{2}\left(\mathrm{r}_{1}=\text { 장경의 반지름, } \mathrm{r}_{2}=\text { 단경의 반지름 }\right)
$$

생식산출력(Reproductive output: RO)의 추정을 위하여 암컷 과 난을 각각 건조기에서 $80^{\circ} \mathrm{C}$ 로 48 시간동안 건조한 후 전자 식 저울(Sartorius BP 201S)로 $0.1 \mathrm{mg}$ 까지 측정하였다. 생식산 출력은 아래의 Clarke et al. (1991) 식을 사용하여 추정하였다.

$$
\mathrm{RO}=\frac{\text { 난의 건중량 }}{\text { 암컷의 건중량 }}
$$

월별 48-60개체의 암컷에 대하여 갑각을 분리한 후 생식 소를 건중량을 난의 건중량과 같은 방법으로 측정하였고 생 식소 중량지수(Gonadosomatic index: GSI)는 다음의 식을 이 용하였다.

$$
\mathrm{GSI}=\frac{\text { 생식소 건중량 }}{\text { 암컷의 건중량 }- \text { 생식소 건중량 }} \times 100
$$

\section{통계분석}

두 종간 평균 난의 부피와 생식산출력의 차이는 변이 (variance)의 동질성 판단 후 분산분석(Analysis of variance: ANOVA)을 통해 검정하였다. 갑각장에 대한 포란수와 난 단 계별 갑각장에 대한 생식소 중량과의 관계는 자연로그로 환산 한 후 회커분석 하였으며, 회귀직선의 기울기와 절편의 차이 는 공분산분석(Analysis of covariance: ANCOVA) (Zar, 1999) 으로 검정하였다. 통계분석은 컴퓨터 프로그램인 MINITAB Version 13.0과 SYSTAT Version 10.0을 이용하였다.

\section{결 과}

포란수, 난의 부피 및 생식산출력(RO)

담수산 새우인 새뱅이 포란암컷의 갑각장은 $5.69-7.85 \mathrm{~mm}$ 였
으며, 포란수는 최소 47 개에서 최대 117 개로 한 마리의 암컷은 평균 $82 \pm 18$ 개의 난을 갖는 것으로 나타났다. 해수산 새우인 넓적뿔고마새우의 포란한 암컷 갑각장은 $4.40-8.91 \mathrm{~mm}$ 였으 며, 포란수는 최소 161 개에서 최대 1,795 개로 평균 $412 \pm 236$ 개 의 난을 갖는 것으로 나타났다. 새뱅이와 넓적뿔꼬마새우 두 종에 대한 갑각장과 포란수의 회귀분석 결과 각 종은 갑각장 이 증가함에 따라 포란수가 유의하게 중가하는 것으로 드러닜 다(Table 1). 두 종의 갑각장에 대한 포란수의 회귀직선을 공분 산분석 한 결과 기울기에 있어서 유의한 차이를 보여주었다 (ANCOVA: $\mathrm{F}=4.63$, d.f. $=1,102, \mathrm{P}<0.05$ ). 이러한 결과는 갑각 장의 증가에 따른 포란수의 증가율이 두 종간 차이가 있다는 것을 의미하며, 갑각장의 증가에 따른 포란수의 증가율은 넓 적뿔꼬마새우가 새뱅이 보다 더 크다는 것을 지적해 준다 (Table 1, Fig. 1).

새뱅이의 난 부피 범위는 $0.57-1.24 \mathrm{~mm}^{3}$ 로 평균 $0.70 \mathrm{~mm}^{3}$ 였 고 넓적뿔고마새우의 난 부피 범위는 $0.23-0.73 \mathrm{~mm}^{3}$ 로 평균 $0.38 \mathrm{~mm}^{3}$ 였으며, 두 종의 난의 부피에 대한 분산분석 결과 새뱅이의 난의 부피가 넓적뿔꼬마새우보다 유의하게 컷다 (ANOVA: $\mathrm{F}=276.06$, d.f. $=1,104, \mathrm{P}<0.001$ ). 한 개체의 포란암 컷이 보유한 난의 건조중량은 새뱅이의 경우 0.0068-0.0185 $\mathrm{g}$ 으로 평균 $0.0127 \mathrm{~g}$ 으로 나타났으며, 넓적뿔꼬마새우의 경우 $0.002-0.0352 \mathrm{~g}$ 으로 평균 $0.0067 \mathrm{~g}$ 으로 나타났다. 암컷의 무게 에서 난의 무게가 차지하는 비로 계산된 생식산출력(RO)은 새뱅이의 경우 $23.62-71.2 \%$ 로 평균 $41.84 \%$ 였고 넓적뿔꼬마새 우는 7.04-58.18\%로 평균 22.67\%였으며, 두 종의 평균 생식산 출력에 대한 분산분석 결과 난의 부피와 마찬가지로 세뱅이의 생식산출력이 넓적뿔꼬마새우보다 높게 나타났다(ANOVA: $\mathrm{F}=82.99$, d.f. $=1,104, \mathrm{P}<0.001$ ).

\section{산란주기 및 빈도}

생식소 중량지수의 월별변화를 관찰한 결과 새뱅이의 경우 1 월부터 3월까지 3.8-4.3으로 낮게 나타났으며, 4월부터 차츰 증가하기 시작하여 5월에 27.5로써 가장 높은 생식소 중량지 수 값을 보여주었다. 이후 7월까지 10 이상의 비교적 높은 생식소 중량지수롤 유지하다가 8월부터 급걱히 감소하는 경 향을 보여주었다(Fig. 2). 넓적뿔고마새우의 경우 5월과 6월에 15.3 과 15.4로써 가장 높은 생식소 중량지수를 보였으며, 7 월 과 8월에 8.8과 9.2로써 약간 감소하였다가 9월에 11.6으로 다시 한번 증가한 후 10 월부터 급격히 낮은 값을 나타내었다 (Fig 2). 생식소 중량지수의 월별 변화에 기초하여 추정된 산란 시기는 두 종 모두 수온이 높은 여름철로 추정되며, 넓적뿔꼬

Table 1. Details of linear regressions for ovigerous females of Neocaridina denticulata denticualta and Laterutes planirostris. Ln egg number (EN) is regressed on Ln carapace length (CL)

\begin{tabular}{lccc}
\hline Species & Regressions & $n$ & $\mathrm{r}^{2}$ \\
\hline N. denticulata denticualta & $\mathrm{LnEN}=1.983 \mathrm{LnCL}+0.555$ & 43 & $0.38^{* * *}$ \\
L. planirostris & $\mathrm{LnEN}=3.023 \mathrm{LnCL}+0.731$ & 63 & $0.74^{* * *}$ \\
\hline
\end{tabular}

\footnotetext{
${ }^{* * *} \mathbf{P}<0.001$.
} 


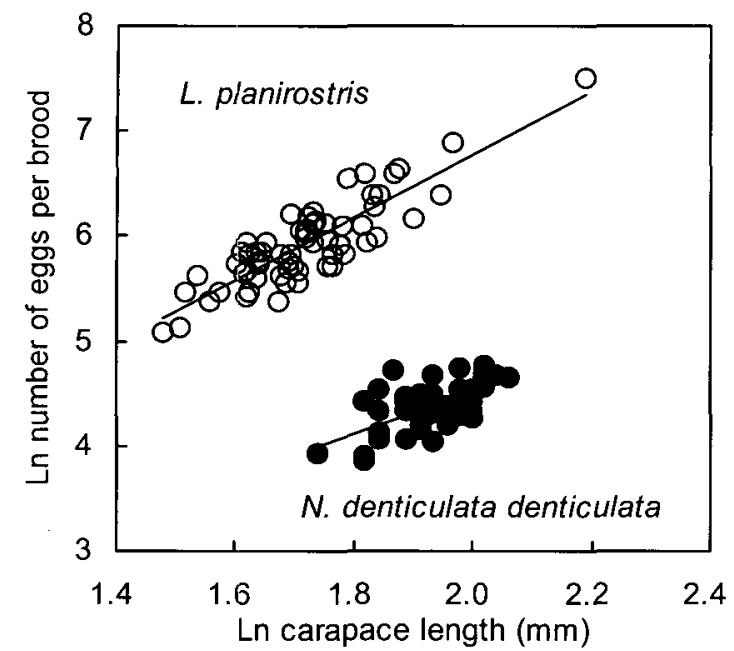

Fig. 1. Regressions of the number of eggs per brood on carapace length of ovigerous female of Neocaridina denticulata denticulata $(\mathbf{O})$ and Latreutes planirostris $(\bigcirc)$.

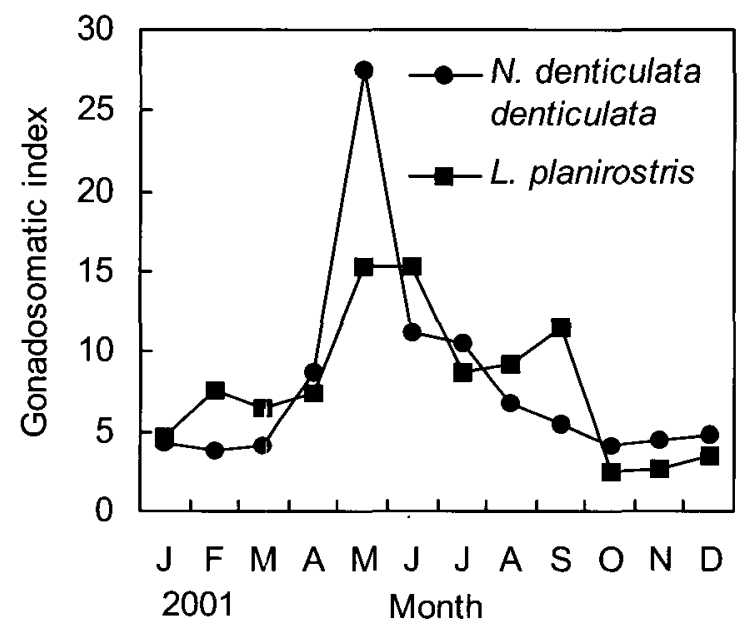

Fig. 2. Monthly changes in the gonadosomatic index of Neocaridina denticulata denticulata and Latreutes planirostris.

마새우는 여름철 산란 후 가을철에 다시 한번 산란에 참여할 가능성이 있는 것으로 추정되었다.

포란한 새뱅이와 넓적뿔꼬마새우의 난 발달 단계별 갑각장 에 대한 생식소 중량은 유의한 상관관계가 있는 것으로 나타
났다(Table 2, Fig. 3). 각 종에 대해서 갑각장과 생식소 중랑간 의 관계가 난 단계별로 차이가 있는지에 대해 기울기와 절편 의 차이를 공분산분석에 의해 검정하였다. 새뱅이에 있어서 난 단계별 갑각장과 생식소 중랑간 회귀직선의 기울기에는 차이가 없는 것으로 드러났다(ANCOVA: $\mathrm{F}=0.05$, d.f. $=1,76$, $\mathrm{P}>0.05)$. 따라서 공통기울기(2.60)를 가정 한 절편의 차이를 분석한 결과 난 단계별로 유의한 차이가 있는 것으로 나타났 는데 눈이 있는 난을 가진 암컷의 생식소 중량이 눈이 없는 난을 가진 암컷의 생식소 중량보다 크다는 것을 지적해 주고 있다(ANCOVA: $\mathrm{F}=48.06$, d.f. $=1,77, \mathrm{P}<0.001$ ). 이러한 결과 는 새뱅이는 난을 발달시키는 동안 생식소를 또 다시 발달시 키는 것을 의미하며, 이는 부화 후 다시 한번 산란에 참여할 수 있다는 가능성을 시사해 주고 있다. 넓적뿔꼬마새우에 있 어서 난 단계별 갑각장과 상식소 중량간 회귀직선의 기울기에 는 차이가 없는 것으로 나타났다(ANCOVA: $\mathrm{F}=3.71$, d.f. $=1$, $110, \mathrm{P}>0.05)$. 따라서 공통기울기(2.46)를 가정 한 절편의 차이 를 분석한 결과 난 단계별로 유의한 차이가 있는 것으로 나타 났다(ANCOVA: $F=206.45$, d.f. $=1,111, \mathrm{P}<0.001$ ). 이러한 결 과는 넓적뿔꼬마새우 역시 새뱅이와 마찬가지로 난을 발달시 키는 동안 생식소를 또 다시 발달시키는 것을 의미하며, 부화 후 다시 한번 산란에 참여할 수 있는 가능성을 시사해 주고 있다.

\section{고 찰}

담수에 서식하는 새뱅이와 해수에 서식하는 넓적뿔꼬마새 우의 평균 포란수는 각각 82 개와 412개로 넓적뿔고마새우가 새뱅이보다 많은 수의 난을 갖는 것으로 나타났지만 평균 난의 부피(새뱅이: $0.7 \mathrm{~mm}^{3}$, 넓적뿔고마새우: $0.34 \mathrm{~mm}^{3}$ )와 생 식산출력(새뱅이: $41.8 \%$, 넓적뿔꼬마새우: $22.7 \%$ )은 새뱅이가 넓적뿔꼬마새우보다 약 두 배정도 높게 나타났다. 갑각장이 증가합에 따른 포란수의 증가율은 갑각장과 포란수간의 회귀 직선에 대한 공분산분석 결과 두 종간 기울기에 있어서 차이 를 보여주었으며, 이러한 결과는 넓적뿔꼬마새우가 새뱅이보 다 갑각장이 증가할수록 포란수의 증가율이 더 크다는 것을 지적해주고 있다. 특히 새뱅이의 생식산출력은 다른 연구자들 에 의한 생이절 새우류의 생식산출력 9-24\% 보다 매우 높게 나타났으며(Clarke, 1987; Lardies and Wehrtmann, 1997; Anger and Moreira, 1998), 담수산 새우류인 Exopalaemon modestus의

Table 2. Details of linear regressions for ovigerous females of Neocaridina denticulata denticualta and Laterutes planirostris with non-eyed eggs and eyed eggs. Ln ovarian dry weight (Odwt) is regressed on Ln carapace length (CL)

\begin{tabular}{clccc}
\hline Species & Egg stage & Regressions & $\mathrm{n}$ & $\mathrm{r}^{2}$ \\
\hline \multirow{2}{*}{ N. denticulata denticualta } & Non-eyed & LnOdwt $=2.76 \mathrm{LnCL}-5.06$ & 35 & $0.14^{*}$ \\
& Eyed & LnOdwt $=2.44 \mathrm{LnCL}-3.57$ & 48 & $0.20^{*}$ \\
\multirow{3}{*}{ L. planirostris } & Non-eyed & LnOdwt $=2.95 \mathrm{LnCL}-3.59$ & 61 & $0.44^{* * *}$ \\
& Eyed & LnOdwt $=1.96 \mathrm{LnCL}-1.06$ & 53 & $0.50^{* * *}$ \\
\hline
\end{tabular}

${ }^{*} \mathrm{P}<0.05$. ${ }^{* * *} \mathrm{P}<0.001$. 

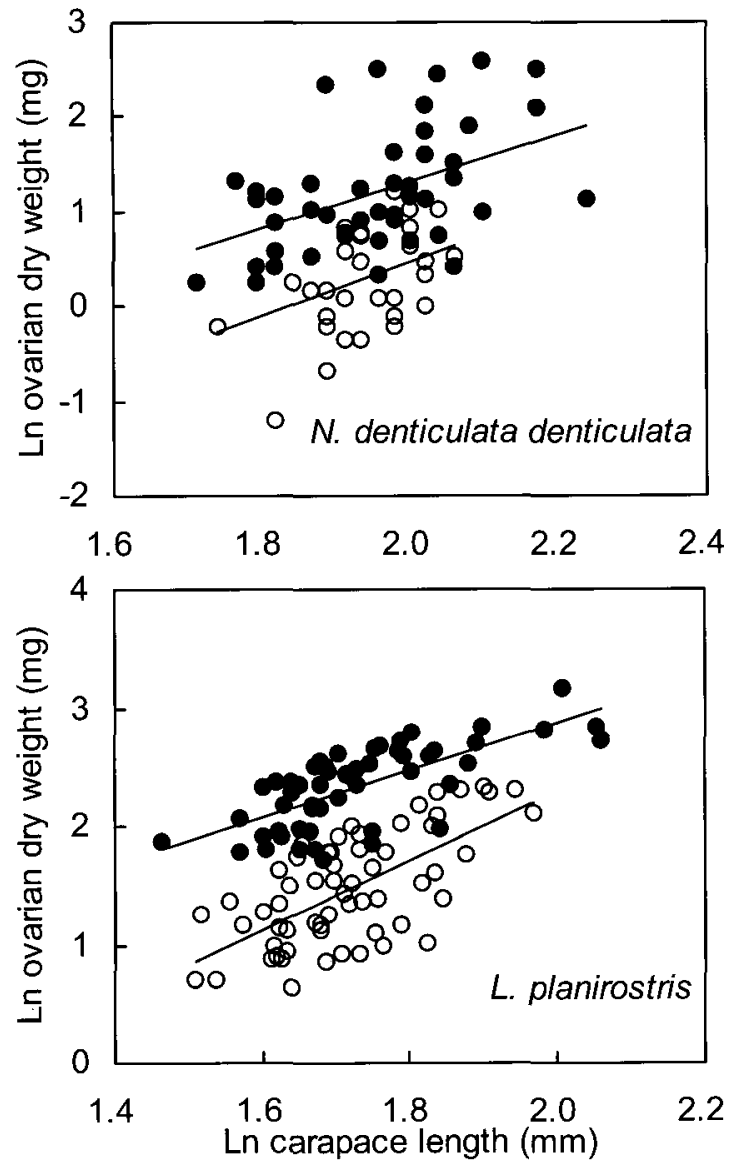

Fig. 3. Regressions of ovarian dry weight on carapace length of ovigerous female of Neocaridina denticulata denticulata and Latreutes planirostris with non-eyed eggs (O) and eyed eggs $(\mathrm{O})$.

$17 \%$ (Oh and Park, 2000)와 Palaemon northropi 의 14\% (Anger and Moreira, 1998) 보다 높은 것으로 드러났다.

난의 크기를 결정하는 요인에 관한 연구는 지금까지 몇몇 연구자에 의해 수행되었다. Clarke 등(1991)은 Pandalus borealis의 위도에 따른 난의 크기의 차이를 분석한 결과 고위 도로 갈수록 보다 큰 난을 갖지만 생식산출력은 위도의 영향 이 없다고 판단하였다. Mashiko $(1990,1992)$ 는 기수산 Marcobrachium nipponese가 해산종보다 작은 크기의 난을 갖 는다는 것을 규명하였으며, 이러한 차이는 특정 환경요인으 로만 결정하기엔 무리가 따르며, 위도, 서식처의 수온, 먹이, 개체군의 구조 및 밀도 등 다양한 요인들이 복합적으로 작용 하여 각각의 환경에 맞는 고유한 생식전략으로 적응한 결과 로 판단하고 있다. 하지만 난의 수가 적은 종에서 난의 크기와 생식산출력이 높게 나타나는 현상은 갑각류에서 일반적으로 나타나고 있으며, 난의 크기가 큰 종은 포란기간이 길고 유생 의 부유기간이 짧기 때문에 생존이 양호한 특징을 갖는 것으 로 잘 알려져 있다(Thorson, 1950; Barnes and Barnes, 1965; Vance, 1973; Wear, 1974). 특히 새뱅이의 경우에는 직접발생
이라는 특징을 가지고 있는데 이러한 발생에 있어서 특징은 큰 크기의 난을 가진 종일수록 직접발생의 가능성이 높다는 것을 지적한 Grant (1990)와 Willows (1990)의 연구결과와 잘 부합되는 것으로 판단된다. 또한 새뱅이는 수심 $1 \mathrm{~m}$ 이내의 산간 계곡에 서식하고 있는데 갈수기에는 물부족으로 인하여 극한 환경에 처해질 가능성이 크기 때문에 한번의 산란기 동안에 다음세대의 생존율을 극대화하기 위해 생식에 투자하 는 에너지가 매우 큰 것으로 판단된다.

본 연구에서 새뱅이와 넓적뿔꼬마새우에서도 난을 발달시 킴과 동시에 생식소를 발달시키는 것으로 나타났다. Pillary and Nair (1971)에 따르면 포란기간 동안 난의 발달과 함께 생식소를 발달시킨다는 것은 부화 후 다시 한번 산란 할 가능 성이 있는 것으로 판단하고 있는데 이러한 현상은 많은 게류 와 새우류에서 발견되고 있다(Hartnoll, 1982; Guerao et al., 1994; Oh and Hartnoll, 1999). Cole (1958)에 따르면 Palaemon serratus 의 경우 프랑스 연안에 서식하는 개체군은 연중 세 번 정도 산란하지만 수온이 보다 낮은 Irish and Welsh 해역에 서식하는 개체군은 연중 한 번만 산란하는 것으로 나타났다. 따라서 산란빈도는 종간 차이가 있을 뿐만 아니라 종내에서 도 개체군에 따라 달라질 수 있으며, 본 연구 대상종인 새뺑 이와 넓적뿔꼬마새우는 연속산란의 가능성이 있는 종들로 판단된다.

\section{사 사}

이 연구는 목포대학교 교내 연구비 지원사업에 의해 수행되 었습니다.

\section{참 고 문 헌}

Anger, K. and G.S. Moreira. 1998. Morphometric and reproductive traits of tropical caridian shrimps. J. Crust. Biol., 18, 823-838.

Barnes, H. and H. Barnes. 1965. Egg size, nauplius size, and their variation with local, geographical, and specific factors in some common cirripes. J. Ani. Ecol., 34, 390-402.

Clarke, A. 1979. On living in cold water: K-strategies in Antarctic benthos. benthos. Mar. Biol., 55, 111-119.

Clarke, A. 1987. Temperature, latitude and reproductive effort. Mar. Ecol. Prog. Ser., 38, 89-99.

Clarke, A.C., C.E. Hopkins and E.M. Nilssen. 1991. Egg size and reproductive output in the deep water prawn Pandalus borealis Krøyer, 1838. Func. Ecol., 5, 724-730.

Cole, H.A. 1958. Notes on the biology of the common prawn Palaemon serratus (Pennant). Fish. Invest. (Series II). 22, 1-22.

Grant, A. 1990. Mode of development and reproductive effort in marine invertbrates: should there be any 
relationship? Func. Ecol., 4, 128-130.

Guerao, G., P.J. Perez-Baquera and C. Ribera. 1994. Growth and reproductive biology of Palaemon xiphias Risso, 1816 (Decapoda: Caridea: Palaemonidae). J. Crust. Biol., 14, 280-288.

Hartnoll, R.G. 1982. Growth. In: The Biology of Crustacea. Embryology, morphology and genetics, Vol. 2, L.G. Abele, ed. Academic Press, New York, 111-185.

Hartnoll, R.G. 1985. Growth, sexual maturity and reproductive output. In: A.M. Wenner, ed., Factors in Adult Growth. A.A. Balkema, Rotterdam, Boston. 101-128.

Hines, A.H. 1982. Allometric constraints and variables of reproductive effort in brachyuran crabs. Mar. Biol., 69, 309-320.

Holthuis, L. B. 1980. FAO species catalogue. Vol. 1: Shrimp and prawns of the world. An annotated catalogue of species of interest to fisheries. FAO Fisheries Synopsis. 125, 1-271.

Kamita T. 1958. Ecological notes on the freshwater shrimps and prawns of Japan VI. On the shrimp, Paratya compressa (De Haan). Zool. Mag., Zool. Soc. Jap., 67, 237-241.

Kim, H.S., 1977. Illustrated Flora and Fauna of Korea. Ministry of Education, Korea, 1-414.

King, M.G. and Butler, A.J. 1985. Relationship of life-history patterns to depth in deep-water caridean shrimps (Crustacea: Natantia). Mar. Biol., 86, 129138.

Lardies, M.A. and I.S. Wehrtmann. 1997. Egg production in Betaeus emarginatus (H. Miline Edwards, 1837) (Decapoda: Alpheidae): Fecundity, reproductive output and chemical composition of eggs. Ophelia, 46, 165-174.

Mashiko, K. 1990. Diversified egg and clutch sizes among local populations of the fresh-water prawn Macrobrachium nipponense (De Haan). J. Crust. Biol., 10,
306-314

Mashiko, K. 1992. Genetic egg and clutch size variations in freshwater prawn populations. Oikos, 63, 454-458.

Oh, C.W. and R.G. Hartnoll. 1999. Size at sexual maturity, reproductive output and seasonal reproduction of Philocheras trispinosus (Hailstone, 1835) (Crustacea: Decapoda) on Port Erin Bay, Isle of Man. J. Crust. Biol., 19, 252-259.

Oh, C.W. and K.Y. Park. 2000. Comparative study on reproductive effort and spawning frequency of the two palaemonid prawns (Exopalaemon modestus and Palaemon gravieri) with different habitats. J. Fish. Sci. Tech., 3, 180-187.

Pillay, K.K. and N.B. Nair. 1971. The annual reproductive cycles of Uca annulipes, Portunus pelagicus and Metapenaeus affinis (Decapada: Crustacea) from the south-west coast of India. Mar. Biol., 11, 152-166.

Strathmann, R.R. 1985. Feeding and unfeeding larval development and life-history evolution in marine invertebrates. Ann. Rev. Ecol. Syst., 16, 339-361.

Thorson, G. 1950. Reproductive and larval ecology of marine bottom invertebrates. Bio. Rev., 25, 1-45.

Vance, R.R. 1973. On reproductive strategies in marine benthic invertebrates. Ame. Nat., 107, 339-352.

Wear, R.G. 1974. Incubation in British decapod crustacea, and the effects of temperature on the rate and success of embryonic development. J. Mar. Biol. Ass. U.K., 54, 745-762.

Willows, R.I. 1990. Mode of development and reproductive effort in marine invertbrates: no relationship predicted by life-history theory? Func. Ecol., 4, 130-132.

Zar, J.H. 1999. Biostatistical Analysis. Prentice Hall Inc., Upper Saddle River, New Jersey, 1-663.

2005년 10 월 10 일 접수

2006년 5월 25일 수리 